\title{
SIMPLE BUCKET CURVATURE FOR DESIGNING A LOW-HEAD TURGO TURBINE FOR PICO HYDRO APPLICATION
}

\author{
Warjito $^{1}$, Budiarso ${ }^{1}$, A.I. Siswantara ${ }^{1}$, Dendy Adanta ${ }^{1}$, M. Kamal ${ }^{1 *}$, R. Dianofitra ${ }^{1}$ \\ ${ }^{1}$ Department of Mechanical Engineering, Faculty of Engineering, Universitas Indonesia, Kampus UI \\ Depok, Depok 16424, Indonesi
}

(Received: November 2016 / Revised: May 2017 / Accepted: October 2017)

\begin{abstract}
The geography of Indonesia renders it difficult to connect many areas to the national electricity grid. To overcome these problems, people need to be able to generate their own electricity. Pico hydro has been proven to be a cost-effective solution for electrification. The Turgo turbine is known for its reliability and strength, and it can perform efficiently with a range of flows. The Turgo's blade consists of an inlet and outlet trail with a curve that joins them. The curve in this study will be made from a simple circle arc to improve manufacturability. Three blades were designed using a basic calculation derived from the velocity triangles, with each blade having a different circle radius. The Computational Fluid Dynamics (CFD) method is used to determine the stream flow through the blade at a level of detail that cannot be obtained using other methods. The boundary conditions used in the study include 2.7 meters of head and a $21 \mathrm{l} / \mathrm{s}$ flow rate, a steady-state homogenous multiphase, and the turbulent models used SST k- $\omega$. The result shows that the Turgo turbine with a $60 \mathrm{~mm}$ arc radius generated $477.7 \mathrm{Watts}$ and has an efficiency of $85.97 \%$, the highest when compared to the other two blades that used $50 \mathrm{~mm}$ and $55 \mathrm{~mm}$ arc radii, respectively.
\end{abstract}

Keywords: CFD; Electrification ratio; Pico-hydro; Turgo turbine

\section{INTRODUCTION}

In 2009, roughly 1.4 billion people had no access to electricity, with a further 1 billion dependent on an unreliable electricity grid (Asian Development Bank, 2009). In a bid to reduce these totals, countries around the world are committing to electrification programs with their local governments and the international community.

The electrification ratio enables a comparison of the number of households that receive electricity with the number of households that do not. Indonesia has an electrification ratio of $81 \%$. This equates to a total of 49 million Indonesians with no access to electricity. In urban areas, the electrification ratio can be as high as $94 \%$, while in rural areas, the electrification ratio can be as low as 66\% (ESDM, 2010).

Pico hydro power is capable of bringing electrification to remote areas where extending the national electricity grid is cost prohibitive and where consumers have very low incomes. In a World Bank report, pico hydro power was cited as being the cheapest opportunity for off-grid generation under $5 \mathrm{~kW}$ in 2005 , and it was still projected to be at least $25 \%$ cheaper than the closest alternative ten years later (Williamson et al., 2014).

\footnotetext{
*Corresponding author's email: mustafakamal250195@gmail.com, Tel: +62-21-7270032, Fax: +62-21-7270033 Permalink/DOI: https://doi.org/10.14716/ijtech.v8i7.767
} 
A hydropower scheme will succeed with the right components and good maintenance. In a hydro scheme development, the type of turbine to be selected is determined by several criteria that depend on the conditions in the desired location. The height from which the water falls, also known as the head, and the flow capacity are the main factors for selecting the turbine.

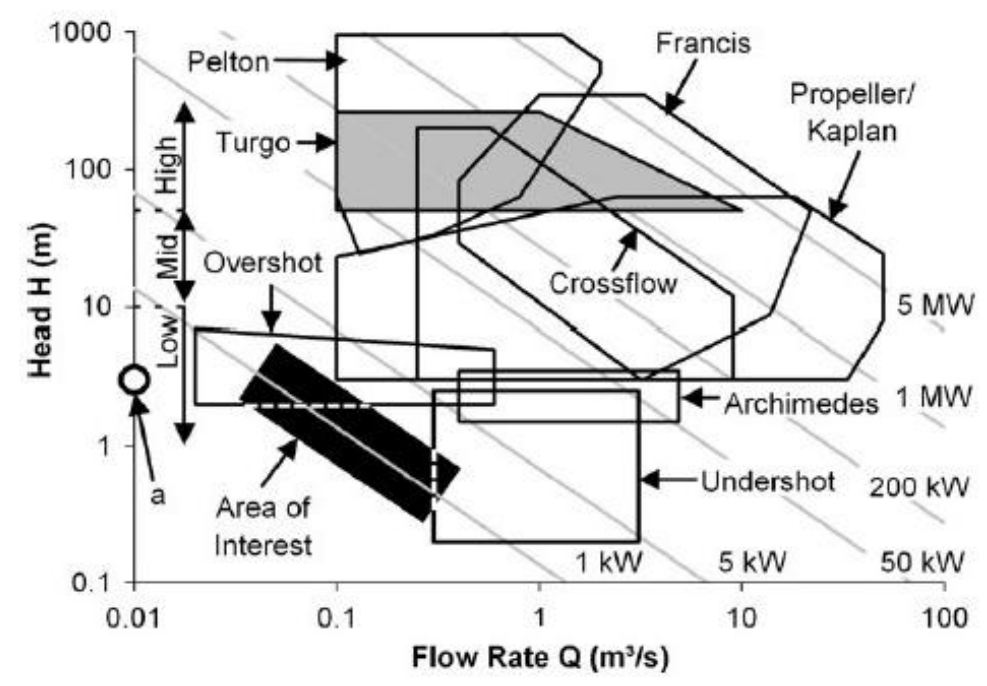

Figure 1 Typical turbine application range chart (Williamson et al., 2014)

Every type of turbine has its own range of head and flow capacity, as seen in Figure 1. It is shown that the Banki Overshot turbine and Undershot turbine are the most suitable types of turbine that can operate in low-head conditions. The propeller turbine is also used in pico hydro as its rotation speed matched with grid frequency (Williamson et al., 2013). So in theory, for pico hydro that requires a low head, this type of turbine is preferable.

The Turgo turbine belongs to the impulse turbine type, along with the Pelton turbine and the Crossflow turbine, wherein the energy exchange is based on the kinetic energy of the water that enters and exits from the turbine under atmospheric pressure. The Turgo turbine is known for its reliability and strength, along with its ability to perform efficiently in a range of flows (Benzon et al., 2016).

The curvature of a Turgo's blade is a specific curve designed to establish a smooth deflection of fluid. Several studies have been conducted to achieve the best curve in order to improve how the blade deflects the flow. The downside of this is that the Turgo's blade is difficult to manufacture. Bearing in mind that the designed Turgo turbine is for a pico hydro scheme, manufacturability will be an important aspect. As a result, the blades that are designed in this study will have the arc of a circle for their curve, thus rendering it possible to make the curve from circular objects.

The purpose of this study is to design a pico-hydro Turgo turbine that can be implemented in remote areas. This study also examines the performance of a blade that uses the arc of a circle for its curve.

\section{DESIGN AND METHODOLOGY}

A hydropower scheme requires flowing water and a certain height (head) in order to produce usable power. The available hydraulic power can be written in terms of head and flow (Harvey, 1993). 


$$
P_{H}=\rho g Q H
$$

The Euler turbine equation can be used to calculate the theoretical power that the turbine generates, assuming a constant blade velocity as the water passes the blade (Munson et al., 1990):

$$
W_{\text {shaft }}=\dot{m}^{*} U^{*}\left(C_{x 1}-C_{x 2}\right)
$$

The flow quantity determines the size of the nozzle that can be used. The diameter of the nozzle can be written as:

$$
D_{j}=2\left(Q / \pi * C_{1}\right)^{1 / 2}
$$

The water emitted from the nozzle is referred to as the jet. The velocity of the jet emanating from the nozzle can be determined using (Harvey, 1993):

$$
C_{1}=C_{v}(2 * g * H)^{1 / 2}
$$

Unlike the Pelton turbine, the jet striking the Turgo blade has an angle of attack of $\alpha$ (Anagnostopoulos et al., 2012). Referring back to the energy transfer stated earlier, the smaller the $\alpha$ the greater the tangential component of the velocity, meaning more power will be generated. The tangential velocity can be calculated using:

$$
C_{x l}=C_{1} \cos \left(\alpha_{1}\right)
$$

The speed ratio is obtained by comparing the blade velocity of the turbine with the jet velocity. In theory, an impulse turbine will have maximum power if the velocity of the blade is equal to half the velocity of the jet (Aaraj et al., 2014). The turbine blade velocity can be written as:

$$
U=\varphi C_{1}
$$

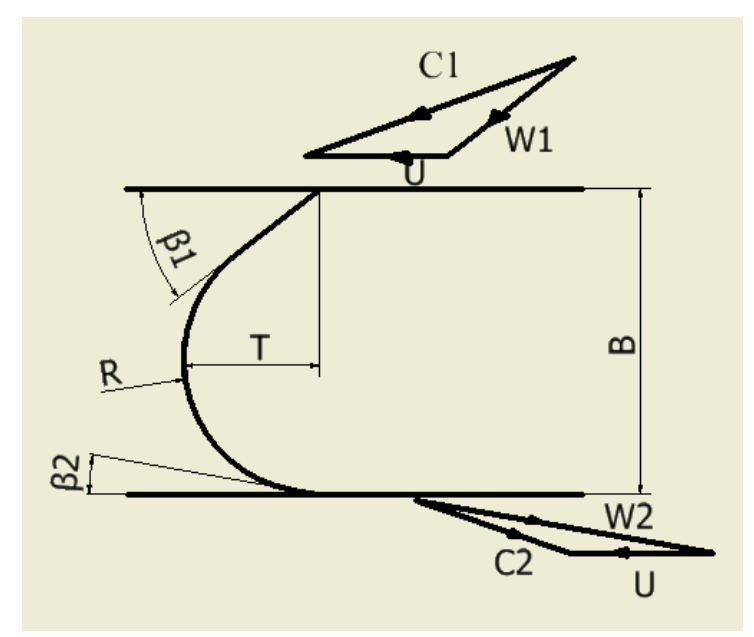

Figure 2 The Turgo turbine velocity triangle and blade parameters

A velocity triangle, as shown in Figure 2, provides an easy way to analyze the energy conversion that is happening between the fluid and the rotor of the turbomachine (Harinaldi, 
2015). The flow of the fluid through the blades in a turbomachine is very complex because it is an unsteady 3D flow. However, the most important analysis in this flow can be carried out using the idealization approach and a simple velocity triangle.

By knowing the values for the jet and blade velocities, it is also possible to determine the relative velocity vector. The relative velocity vector can provide information as to the value and direction of the jet velocity relative to the Turgo blade. This value can be derived using simple trigonometric rules in the velocity triangle, as shown in Figure 2.

$$
W_{1}=C_{1}+U-2 * C_{1} * U^{*} \cos \left(\alpha_{1}\right)
$$

One of the main parameters in the design of a Turgo turbine is the relative inlet angle $(\beta 1)$. The relative inlet angle of the water is assumed to be parallel to the blade's inlet edge for smooth entry in order to prevent hydraulic shock or a water hammer (Gaiser et al., 2016). This condition must therefore be avoided. The relative inlet angle can also be obtained using simple trigonometric rules in the velocity triangle:

$$
\beta_{1}=180^{0}-\cos ^{-1}\left[\left(W_{1}^{2}+U^{2}-C_{1}\right)^{2} /\left(2 * U^{*} W_{1}\right)\right]
$$

In actual cases, friction is presented and the relative velocity will be different in the inlet and outlet. For simplicity, the value of the relative velocity reduction due to friction will be calculated by assuming a friction coefficient $k$ that is equal to the ratio of the relative exit velocity to the relative inlet velocity (Gaiser et al., 2016):

$$
k=\mathrm{W}_{2} / \mathrm{W}_{1}
$$

The smaller the relative exit angle the greater the force produced by the water, hence the more power is produced. But there is a limitation in this value due to the design of the turbine runner itself. A smaller angle leads to a greater chance that the water exiting the blade will hit the back of the incoming blade, which will reduce the efficiency. There is no exact equation for obtaining a value where the relative exit angle is sufficiently small to produce more power but large enough for the water to not hit the incoming blade, as this problem accounts for the spacing of the blades and the complex $3 \mathrm{D}$ flow.

The water absolute exit velocity can be calculated using the velocity triangle:

$$
C_{2}^{2}=W_{2}^{2}+U^{2}-2 * W_{2} * U^{*} \cos \left(\beta_{2}\right)
$$

The angle $\alpha_{2}$ can be obtained by applying trigonometric rules to the velocity triangle:

$$
\alpha_{2}=180^{0}-\cos ^{-1}\left[\left(C_{2}^{2}+U^{2}-W_{2}^{2}\right) /\left(2 * C_{2} * U\right)\right]
$$

The tangential component of the water velocity in the exit section can be written as:

$$
C_{x 2}=C_{2} * \cos \left(\alpha_{2}\right)
$$

The efficiency can be calculated by dividing the turbine's theoretical power by the available hydraulic power:

$$
\eta=W_{\text {shaft }} / P_{H}
$$




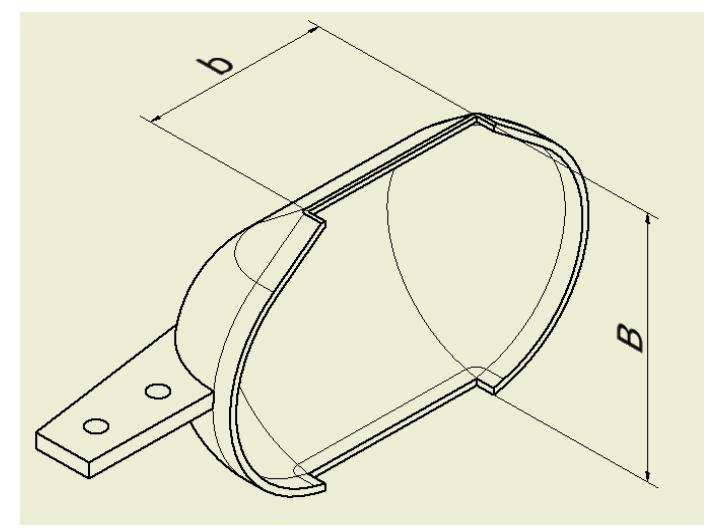

Figure 3 The Turgo blade

Figure 3 shows the width of the inlet section (b) and the height (B). The width of the inlet section (b) must be long enough to ensure that the whole jet passes through the blade. As for the blade height B, no specific value has been suggested by previous authors. Benzon et al. (2016) suggests that the blades should be short enough to reduce frictional losses to the relative velocity, but long enough to prevent eddy losses due to the bending of the water as it travels across the blades (Benzon et al., 2016).

The runner diameter of the Turgo turbine determines the speed at which the turbine rotates. The smaller the diameter, the faster it rotates. The Turgo's runner geometry is designed to allow a much smaller runner diameter for a particular jet diameter, a $D_{r} / D_{j}$ ratio of 5.25:1. This compares to the Pelton wheel that is restricted to a ratio of 10:1. Cobb et al. (2013) used a 15.2$21.3 D_{r} / D_{j}$ for the $169 \mathrm{~mm}$ turbine and a $10.3-16.5 D_{r} / D_{j}$ for the $131 \mathrm{~mm}$ turbine (Cobb et al., 2013). Williamson et al. (2013) used a 5-10 $D_{r} / D_{j}$ that resulted in a best-performing design with the 7.5 $D_{r} / D_{j}$ (Williamson et al., 2013). Gaiser et al. (2016) obtained an optimum value for $D_{r} / D_{j}$ using a response surface methodology, which was 8.5:1 (Gaiser et al., 2016).

Table 1 Ratio between depth of blade (T) and height (B)

\begin{tabular}{cc}
\hline Arc $(\mathrm{mm})$ & T/B \\
\hline R50 & 0.487228583 \\
R55 & 0.440069355 \\
R60 & 0.392902305 \\
\hline
\end{tabular}

Three blades were designed in line with the equations above. The equations above are good only for establishing the angle of the blade's inlet edge, since it was stated earlier that the angle of the inlet edge is assumed to be the same as the relative inlet angle to prevent hydraulic shock. Three arcs of a circle with different radii are used for the curvature of each blade.

Each type of blade has a different depth from the others. This is due to the arcs starting at a different location in the inlet trail. The ratios of the depth $(T)$ to the height $(B)$ of the blades are shown in Table 1.

Several previous studies have also used the same software to simulate the performance of a turbine. Correa et al. (2012) developed a methodology for the design of a Turgo turbine using Rankine ovoids and simulated the designed turbine using ANSYS 12,0 (Correa et al., 2012). All 20 blades and their casings were simulated using a very coarse mesh. Benzon et al. (2016) used a transient Computational Fluid Dynamics (CFD) analysis to simulate a Gilkes Turgo turbine 
(Benzon et al., 2016). The SST k- $\omega$ turbulence model and homogeneous multiphase model were used.

The steady-state homogenous multiphase simulation in this study was carried out with only three blades and a portion of the runner to minimize the computation power needed. A mesh independence test was conducted and a total of over 500,000 elements were simulated. The SST $\mathrm{k}-\omega$ turbulence model was used as it is better able to predict the flow on a near-wall area than $\mathrm{k}-$ $\varepsilon$ (Bijukchhe, 2012).

\section{RESULTS AND DISCUSSION}

The pico-hydro Turgo turbine that will be designed in this study is intended to be tested in Salam Lake, University Indonesia. The height difference between the lake surface and the turbine is $2.7 \mathrm{~m}$. A portable triangular V-notch weir was used to measure the flow in the channel that is connected to the pipe with a nozzle in the end. The measured flow is $21.1 \mathrm{l} / \mathrm{s}$. Using these data and assuming a gravity acceleration of $9.8 \mathrm{~m} / \mathrm{s}^{2}$ and a water density of 1000 $\mathrm{kg} / \mathrm{m}^{3}$, the available hydropower is:

$$
P_{H}=\rho g Q H=1000 \times 9.8 \times 0.021 \times 2.7=555.66 \text { watts }
$$

The speed of the water emanating from the nozzle can be calculated by assuming a 0.9 nozzle discharge coefficient:

$$
C_{1}=C_{v}(2 * g * H)^{1 / 2}=0.9(2 \times 9.8 \times 2.7)^{1 / 2}=6.547 \mathrm{~m} / \mathrm{s}
$$

If we know the flow of the water and the speed it travels, the nozzle diameter can be calculated:

$$
D_{j}=2\left(Q / \pi^{*} C_{1}\right)^{1 / 2}=2(0.021 / \pi \times 6.547)^{1 / 2}=63.9 \mathrm{~mm}
$$

The runner diameter can be obtained by specifying the runner diameter to the jet diameter ratio. The 8.5 $\mathrm{Dr} / \mathrm{Dj}$ will be used as it is consistent with the literature and will result in a smaller diameter.

$$
D_{r}=8.5 D_{j}=8.5 \times 63.9=543.33 \mathrm{~mm}
$$

By choosing an angle of attack $\left(\alpha=20^{\circ}\right)$, the relative inlet velocity and the relative inlet angle can be obtained.

$$
\begin{aligned}
& W_{1}^{2}=6.547^{2}+3.27^{2}-2 \times 6.547 \times 3.27 \times \cos \left(20^{\circ}\right)=3.646 \mathrm{~m} / \mathrm{s} \\
& \beta_{1}=180^{\circ}-\cos ^{-1}\left[\left(3.646^{2}+3.27^{2}-6.547^{2}\right) /(2 \times 3.27 \times 3.646)\right]=37.788^{0}
\end{aligned}
$$

The relative outlet velocity value depends on the friction coefficient $k$. For a well-designed blade, $k$ is typically in the range $0.9-0.95$.

$$
W_{2}=0.9 \times 3.464=3.282 \mathrm{~m} / \mathrm{s}
$$

Experiments indicate that a discharge angle of $15-20^{\circ}$ performs the best. With this, the absolute exit velocity and the angle $\alpha_{2}$ can be calculated by assuming a constant blade velocity of $U_{\text {inlet }}=$ $\mathrm{U}_{\text {outlet. }}$

$$
\begin{aligned}
& C_{2}{ }^{2}=3.282^{2}+3.27^{2}-2 \times 3.282 \times 3.27 \cos (15)=0.571 \mathrm{~m} / \mathrm{s} \\
& \alpha_{2}=180^{\circ}-\cos ^{-1}\left[\left(0.571^{2}+3.27^{2}-3.282^{2}\right) /(2 * 0.561 * 3.27)\right]=94.09^{0}
\end{aligned}
$$

To calculate the theoretical power produced by the turbine, the tangential component of the water velocity must be calculated.

$$
C_{x l}=6.547^{*} \cos \left(20^{\circ}\right)=6.152 \mathrm{~m} / \mathrm{s}
$$




$$
C_{x 2}=0.571 * \cos \left(94.09^{\circ}\right)=-0.0403 \mathrm{~m} / \mathrm{s}
$$

The negative sign indicates that the exit velocity is in the opposite direction to the inlet velocity. Hence the theoretical power is:

$$
W_{\text {shaft }}=40 \times 3.27(6.152-(-0.0403))=429.953 \text { watts }
$$

Figure 4 shows that the turbine will theoretically have a maximum efficiency of $75.6 \%$ when the speed ratio is 0.5 .

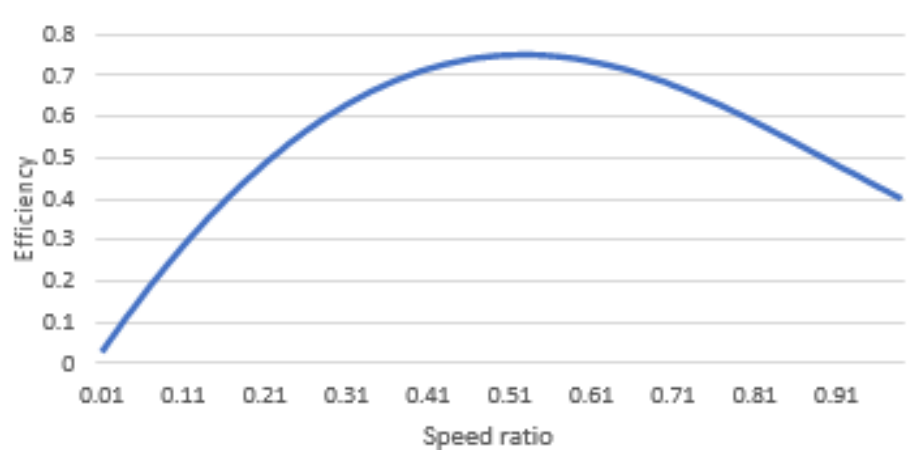

Figure 4 Efficiency-versus-speed ratio

The height of the blade $(B)$ should be twice the jet diameter, and the width $(b)$ is $1.5 D_{j}$. Thus, the blade height is $127.84 \mathrm{~mm}$ and the width of the inlet section is $95.88 \mathrm{~mm}$.

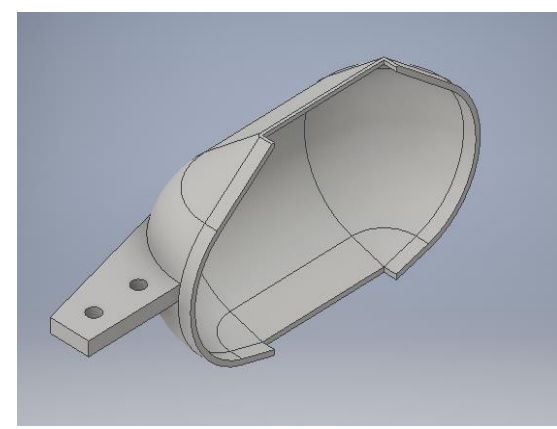

(a)

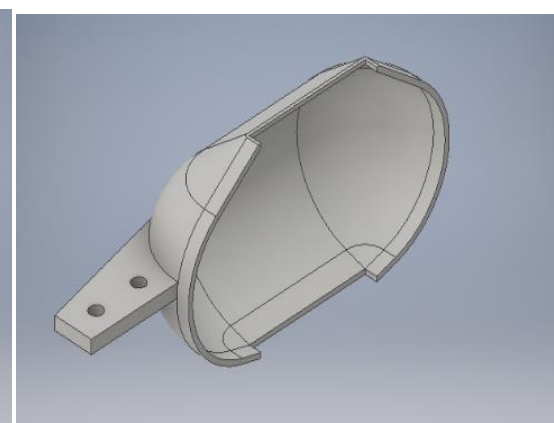

(b)

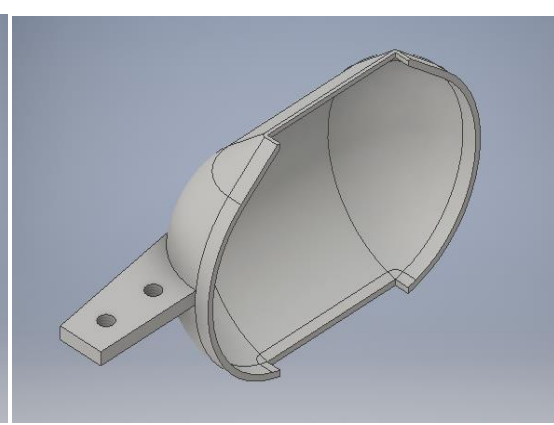

(c)

Figure 5 The designed Turgo blades: (a) radius of $\operatorname{arc}=50 \mathrm{~mm}$; (b) radius of arc $=55 \mathrm{~mm}$; and (c) radius of $\operatorname{arc}=60 \mathrm{~mm}$

Three types of blade were designed, each with a different arc radius, as shown in Figure 5. The difference in the arc radius leads to a difference in the length the water must travel across the blade, with the greatest arc radius having the smallest travel distance. The inlet and outlet trails of the blades are also different, with the biggest arc radius having the shortest inlet and outlet trails. The $60 \mathrm{~mm}$ arc radius blade has a very short outlet trail, which means that increasing the arc radius further would produce a blade that either has no outlet trail or requires an increase in the blade's height.

The simulation above shows that there is a portion of the exiting water that still hits the oncoming blade, indicating that the blade's outlet angle is not big enough. It can be seen in Figure 7 that the flow of water spreads in a radial direction to comply with the shape of the bucket, which is also the case in Figure 6. 
Table 2 Simulation results

\begin{tabular}{ccccc}
\hline $\begin{array}{c}\text { Arc } \\
(\mathrm{mm})\end{array}$ & T/B & $\begin{array}{c}\text { Torque } \\
(\mathrm{Nm})\end{array}$ & $\begin{array}{c}\text { Power } \\
(\text { Watt })\end{array}$ & $\begin{array}{c}\text { Efficiency } \\
(\%)\end{array}$ \\
\hline 50 & 0.487228583 & 53.13 & 446.292 & 80.31 \\
55 & 0.440069355 & 55.6 & 467.04 & 84.05 \\
60 & 0.392902305 & 56.87 & 477.708 & 85.97 \\
\hline
\end{tabular}

Table 2 shows the power and efficiency that resulted from the simulation. In the case of the 55 and $50 \mathrm{~mm}$ arc radius blades, it can be seen that the portion of water exiting from the outer-side blade is smaller than that for the $60 \mathrm{~mm}$ arc radius blade, indicating that a large depth of blade generates too great a reduction in the kinetic energy. The $60 \mathrm{~mm}$ arc radius blade yielding the shortest travel distance for the water means that the amount of friction to which the water is subjected is reduced compared to the other blades. This is expected to be one of the causes of the maximum efficiency achieved by the $60 \mathrm{~mm}$ arc radius blade. The same table shows that a smaller ratio of depth to height $(T / B)$ produced more power.

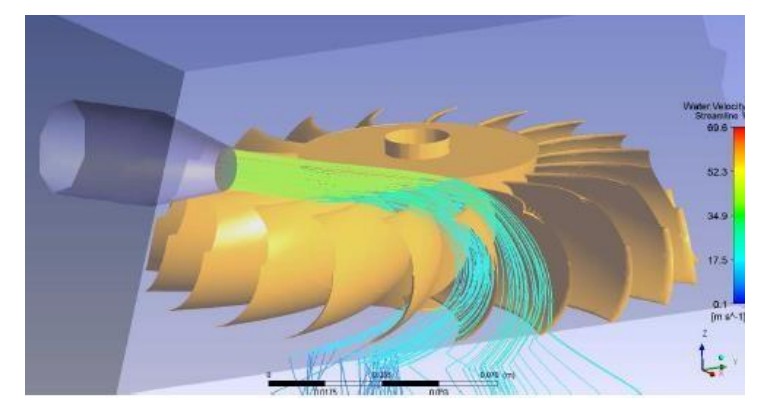

Figure 6 Streamlines passing through the buckets (Correa et al., 2012)

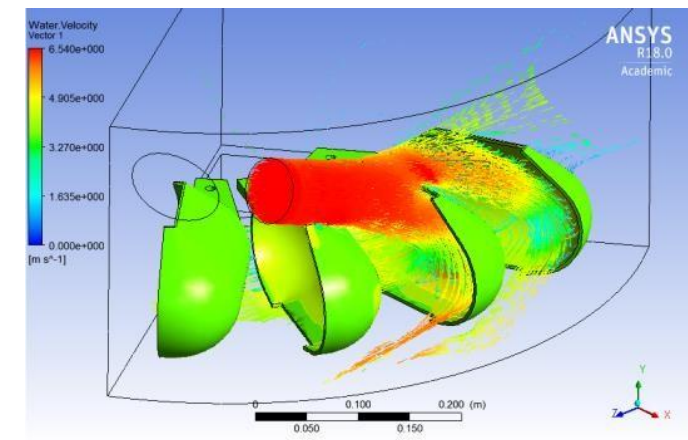

(a)

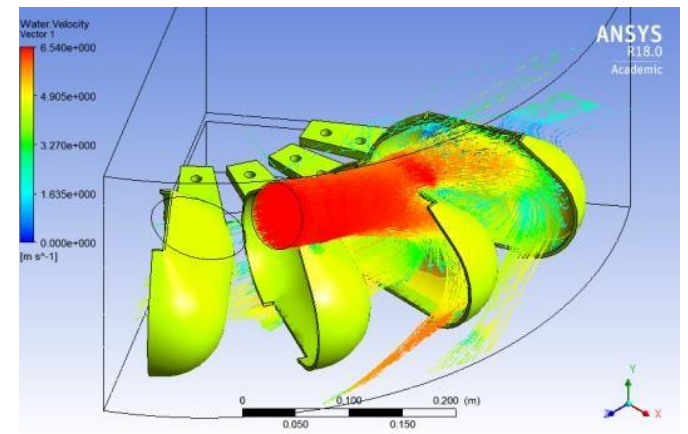

(b)

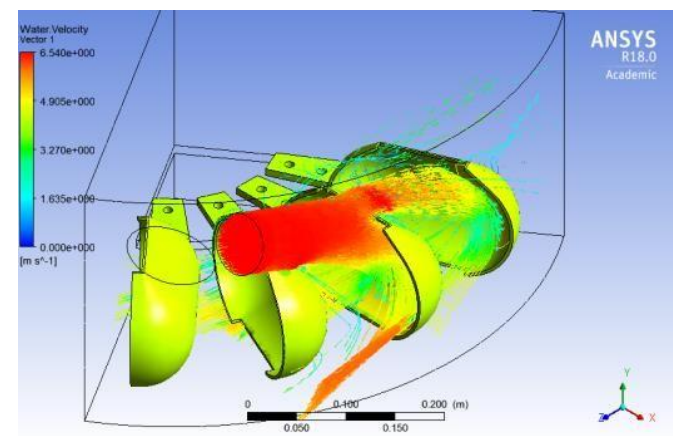

(c)

Figure 7 Flow simulation in the Turgo blade, with: (a) radius of arc $=50 \mathrm{~mm}$; (b) radius of arc $=$ $55 \mathrm{~mm}$; and (c) radius of $\operatorname{arc}=60 \mathrm{~mm}$ 


\section{CONCLUSION}

The theoretical power that is developed from the analytical calculation is 429.953 watts, with a maximum efficiency of $75.6 \%$. A steady-state homogenous multiphase simulation is conducted to know the flow condition along each blade. The simulation shows that the $60 \mathrm{~mm}$ arc radius blade generated 477.708 watts with an $85.97 \%$ efficiency at a head of $2.7 \mathrm{~m}$, speed ratio of 0.5 , and a flow rate of $0.021 \mathrm{~m}^{3} / \mathrm{s}$, which was the highest when compared to the other blades.

\section{ACKNOWLEDGEMENT}

The authors would like to express their thanks to KEMENRISTEK DIKTI, which has funded this research with grant No. SP. DIPA-042.06.1.401516/2016.

\section{REFERENCES}

Aaraj, Y., Mortada, S., Clodic, D., Nemer, M., 2014. Design of a Turgo Two-phase Turbine Runner. In: $15^{\text {th }}$ International Refrigeration and Air Conditioning Conference, pp. 1-8

Anagnostopoulos, J.S., Koukouvinis, P.K., Stamatelos, F.G., Papantonis, D.E., 2012. Optimal Design and Experimental Validation of a Turgo Model Hydro Turbine. In: ASME 2012 $11^{\text {th }}$ Biennial Conference on Engineering Systems Design and Analysis, ASME Paper No. ESDA2012-82565, pp. 157-166

Asian Development Bank, 2009. Energy Outlook for Asia and the Pacific. Mandaluyong, Philippines

Benzon, D.S., Aggidis, G.A., Anagnostopoulos, J.S., 2016. Development of the Turgo Impulse Turbine: Past and Present. Applied Energy, Volume 166(Supplement C), pp.1-18

Bijukchhe, V., 2012. Comparison of Experimental Results of Horizontal Kaplan Turbine with Computational Fluid Dynamics. The University of Iowa

Cobb, B.R., Sharp, Kendra, V., 2013. Impulse (Turgo and Pelton) Turbine Performance Characteristics and Their Impact on Pico-hydro Installations. Renewable Energy, Volume 50(Supplement C), pp.959-964

Correa, J.L.C., De Andrade, J., Asuaje, M., 2012. A Preliminary Analysis of a Turgo Type Turbine CFD Simulation Designed with an Integrated Dimensional Methodology. In: ASME 2012 Fluids Engineering Division Summer Meeting Collocated with the ASME 2012 Heat Transfer Summer Conference and the ASME $201210^{\text {th }}$ International Conference on Nanochannels, Microchannels, and Minichannels, American Society of Mechanical Engineers, pp. 327-337

ESDM, 2010. Handbook of Energy \& Economic Statistics of Indonesia. Jakarta: ESDM

Gaiser, K., Erickson, P., Stroeve, P., Delplanque, J.-P., 2016. An Experimental Investigation of Design Parameters for Pico-hydro Turgo Turbines using a Response Surface Methodology. Renewable Energy, Volume 85, pp. 406-418

Harinaldi, B., 2015. Fluid Systems; Basic Principles and Application of Fluid Engines, Hydraulic Systems and Pnuematic Systems (Sistem Fluida; Prinsip Dasar dan Penerapan Mesin Fluida, Sistem hidrolik dan Sistem Pnuematik). Jakarta: Erlangga (in Bahasa)

Harvey, A., 1993. Micro-Hydro Design Manual: A Guide to Small-scale Water Power Schemes. Intermediate Technology Publications

Munson, B.R., Young, D.F., Okiishi, T.H., 1990. Fundamentals of Fluid Mechanics. Wiley; 1 edition (1600)

Williamson, S.J., Stark, B.H., Booker, J.D., 2014. Low Head Pico Hydro Turbine Selection using a Multi-criteria Analysis. Renewable Energy, Volume 61, pp.43-50

Williamson, S.J., Stark, B.H., Booker, J.D., 2013. Performance of a Low-head Pico-hydro Turgo Turbine. Applied Energy, Volume 102(Supplement C), pp.1114-1126 